\title{
ENHANCING CARBON SEQUESTRATION POTENTIAL OF URBAN GREEN SPACES THROUGH TRANSFER OF DEVEOPMENT RIGHTS STRATEGY
}

DOI: https://doi.org/10.18509/AGB.2018.02

UDK: 502.12:[504.5:546.26

\author{
Riccardo Privitera ${ }^{1}$, Daniele La Rosa ${ }^{2}$ \\ ${ }^{1,2}$ Department of Civil Engineering and Architecture, University of Catania, Italy \\ Corresponding author: riccardo.privitera@darc.unict.it
}

Submitted: January 2017, Accepted: May 2017, Published: October 2017

\begin{abstract}
Non-urbanized areas (NUAs) play an important role in reducing the effects of climate change by providing both carbon storage and sequestration. Despite their importance, they are endangered by urbanization pressures and often neglected by local spatial planning practices. On the contrary, NUAs should be protected and designed as new public urban green spaces to enhance the amount of vegetation of different land cover types and therefore their potential capacity of carbon sequestration. This study proposes a three steps-method for enhancing carbon sequestration of NUAs through the implementation of new public green spaces while ensuring the related economic feasibility of urban development based on a Transfer of development rights program.
\end{abstract}

Key words: Non urbanized areas, Land covers, Carbon sequestration, Transfer of development rights, Urban green spaces

\section{Introduction}

Cities play a key role in the rise of greenhouse gases emissions, which is considered to be one of the main causes of global warming and climate change. An important role in reducing the effects of climate change can be played by Non-Urbanized Areas (NUAs). They are fragments of woods, shrubs, herbaceous vegetation fields, abandoned farmlands, and other different types of urban green spaces with amounts of vegetation that represent the last remnants of nature scattered within urban areas [1]. NUAs produce multiple urban ecosystem services mainly carbon storage and sequestration [2], regulation of microclimate and mitigation of urban heat islands, and cultural and recreational opportunities. Despite their importance in contributing to climate change risks adaptation in cities [1], NUAs suffer from surrounding urbanization pressures and are often neglected by local spatial planning practices especially in Southern Europe urban contexts [3]. On the contrary, NUAs should be protected and designed as new public urban green spaces to enhance their ecosystemic potential through increasing the amount of vegetation cover. Nevertheless, the implementation of new public urban green spaces has to deal with land acquisition of plots of NUAs belonging to private owner. Effectively, public acquisition of land is often economically unsustainable for local administration and face resistance from private landowners [4]. The issue of economic feasibility for managing public intervention and providing accessible public urban green spaces could be addressed through incentive-based approaches, including the Transfer of Development Rights [5]. A Transfer of Development Rights (TDR) programme defines an area to be protected from development and one where development will be allowed to occur. Landowners can transfer the rights from the area to be protected (sending area) to the area to be developed (receiving area). As a consequence, the parcel from which the development rights are being transferred can no longer be developed, or be developed only in a limited way. As a result, landowners are compensated for 
regulatory restrictions that reduce the property values. In this direction, the paper proposes a three steps-method for enhancing carbon sequestration of NUAs through the implementation of new public green spaces while ensuring the related economic feasibility of urban development based on a TDR program.

\section{Materials and methods}

The presented case study is the metropolitan area of Catania, the largest in Sicily that experienced during the past five decades an impressive urban growth characterized by high urban density and a severe lack of public green spaces. In the course of forty years (1961-2001), the total population of $27 \mathrm{mu}-$ nicipalities included in the metropolitan area grew more than $27 \%$. In 2008, approx. $60 \%$ of its total population lived outside the main city, indicating progressive population expansion beyond the city center. The methodology is structured as following:
First step - Selecting and designing NUAs patches compound

The patches of NUAs included in the urban fabric are selected as appropriate sites for arranging new public green spaces according to the following criteria [6]:

- their current land-use is abandoned farmland or uncultivated lands characterized by presence of trees, shrubs or seasonal herbaceous vegetation;

- they are mainly non-built areas with high proximity to other residential areas or public transport nodes;

- the ownership of land is mainly private;

- they have an appropriate location and shape for defining the city green infrastructure and enhancing the endowment of other key public services.

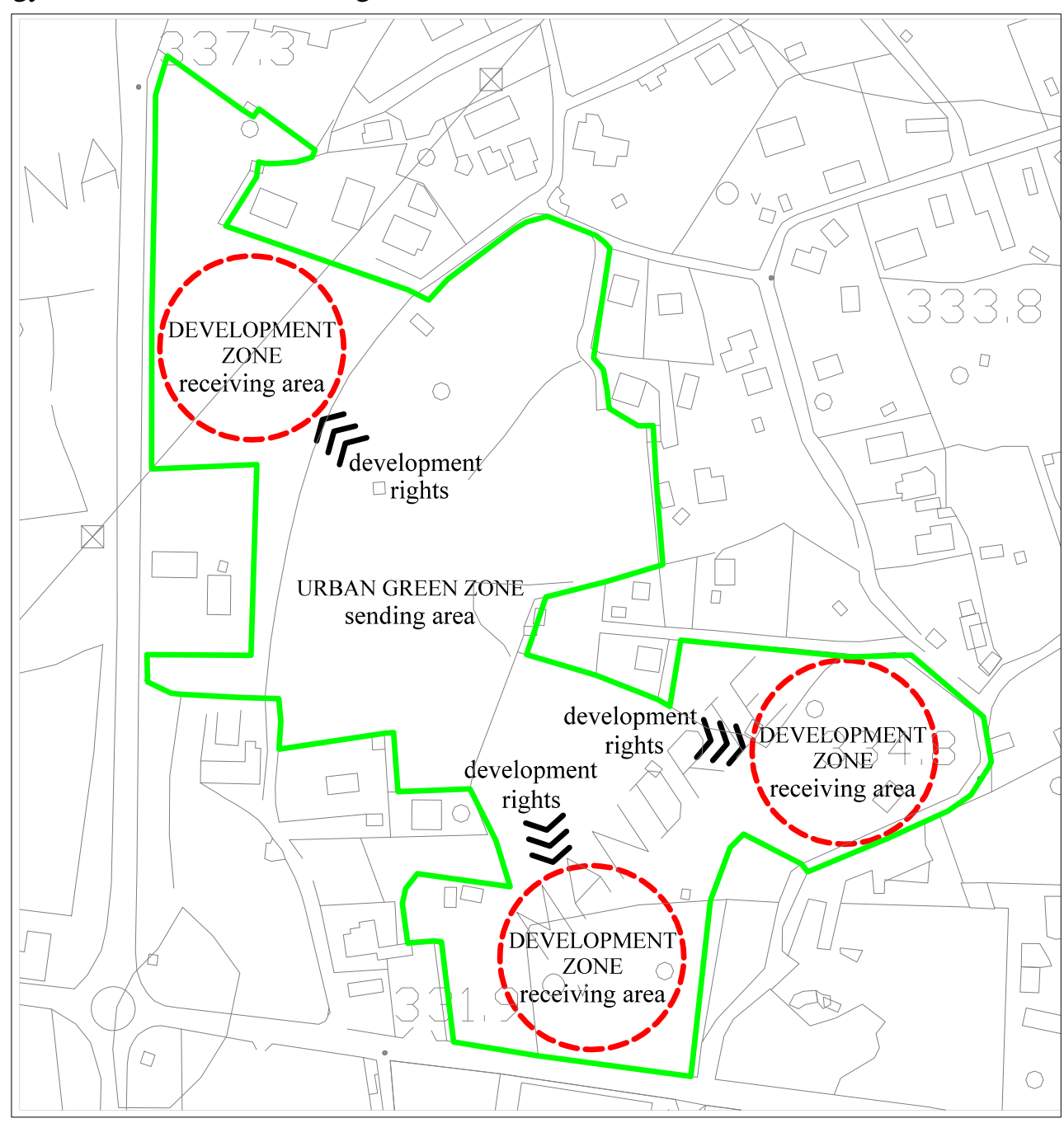

Figure 1: Urban green zone and Developments zones within a NUAs patches compound 
The selected NUAs patches identify a compound where 'Development Zones' and 'Urban green Zone' are identified. Development Zones represent the areas where the urban development will be occur while Urban green Zone represents the areas for new public green spaces (Fig. 1).

Second step - assessing economic feasibility of urban development

The local TDR program assigns to each compound of NUAs the status of sending area while Development Zones (as subsets of the compound) represent both sending and receiving area (Fig. 1). The total amount of development rights are assigned to the private land parcels included within this compound and transferred to the Development Zones designated for new urban development. Within the Development Zones, the transferred development rights will be added to the ones generated by Development Zones themselves. As a result, new buildings can be built and the majority of NUAs parcels (Urban green Zone) are transferred to public property.

Amount of development rights to be assigned to compound land parcels and size of
Development Zones are identified according to an Economic feasibility assessment Tool (Tab. 1). In order to ensure the economic feasibility of the urban transformation, the proposed tool quantifies the equitable development rights to be assigned to private land parcels in terms of FAR, that is intended as volume of buildings $\left(\mathrm{m}^{3}\right)$ over the land parcel unit $\left(=1.00 \mathrm{~m}^{2}\right)$. Percentage of Urban green Zone (G\%) takes into account the economic rates of land parcels to be left (RLP), total development cost rates (KT), and final economic rate of the built-up property (RP). According to this tool, the overall urban development can be considered as a feasible investment project when net profit ratio for private developers $(\mathrm{P} \%)$ results more than $25 \%$, that is considered by the Italian Urban Developers National Association a reasonable percentage value of profit. Net profit ratio is expressed in terms of total amount of profit $(\mathrm{P})$ compared to the final economic value of development rights (VDR) and represents the final economic earnings for developers compared to the total revenues obtained after selling the new built-up properties.

\begin{tabular}{|c|c|c|c|c|}
\hline \multicolumn{5}{|c|}{ ECONOMIC FEASIBILITY ASSESSMENT TOOL } \\
\hline \multirow{8}{*}{ 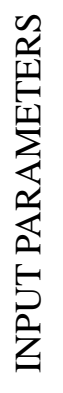 } & economic rates of local properties & & & \\
\hline & economic rate of agricultural land parcel & RLP & 6,00 & $€ / \mathrm{m}^{2}$ \\
\hline & economic rate of property & $\mathrm{RP}$ & $1.400,00$ & $€ / \mathrm{m}^{2}$ \\
\hline & urban development parameters & & & \\
\hline & Urban green area percentage & $\mathrm{G} \%$ & 75,00 & $\%$ \\
\hline & Floor Area Ratio & FAR & 0,40 & $\mathrm{~m}^{3} / \mathrm{m}^{2}$ \\
\hline & land parcels area & AP & $72.948,16$ & $\mathrm{~m}^{2}$ \\
\hline & total development cost rates & KT & $1.006,72$ & $€ / \mathrm{m}^{2}$ \\
\hline \multirow{11}{*}{ 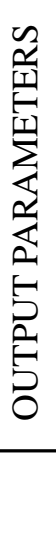 } & urban development features & & & \\
\hline & economic value of land parcel & VLP=AP X RLP & $437.688,96$ & $€$ \\
\hline & land parcels to be transferred area & $\mathrm{AT}=\mathrm{AP} \times \mathrm{G} \%$ & $54.711,12$ & $\mathrm{~m}^{2}$ \\
\hline & economic value of land to be transferred & $\mathrm{VT}=\mathrm{AT} \mathrm{X} \mathrm{RLP}$ & $328.266,72$ & $€$ \\
\hline & development zone area & $\mathrm{DZA}=\mathrm{AP}-\mathrm{AT}$ & $18.237,04$ & $\mathrm{~m}^{2}$ \\
\hline & total amount of development rights & $\mathrm{DR}=\mathrm{AP} \times \mathrm{FAR}$ & $29.179,26$ & $\mathrm{~m}^{3}$ \\
\hline & developable floor area & $\mathrm{DFA}=\mathrm{DR} / 3,20$ & $9.118,52$ & $\mathrm{~m}^{2}$ \\
\hline & total development costs & $\mathrm{KDC}=\mathrm{DFA} \times \mathrm{KT}$ & $9.179 .796,45$ & $€$ \\
\hline & economic value of development rights & $\mathrm{VDR}=\mathrm{DR} \times \mathrm{RP} / 3,20$ & $12.765 .928,00$ & $€$ \\
\hline & total amount of profit & $\mathrm{P}=\mathrm{VDR}-\mathrm{KDC}-\mathrm{VT}$ & $3.257 .864,83$ & $€$ \\
\hline & NET PROFIT RATIO $(\geq 25 \%)$ & $\mathrm{P} \%=\mathrm{P} / \mathrm{VDR} \times 100$ & 25,52 & $\%$ \\
\hline
\end{tabular}

Table 1: Economic feasibility assessment Tool. 
Third step - Increasing vegetation cover for carbon sequestration enhancement

As a consequence of new urban development within the Development Zones, some vegetation is substituted with impervious land covers. This implies a loss of ecosystem services and particularly loss of carbon sequestration potential produced by the lost vegetation. On the other side, the new public acquired Urban green Zone allows to implement a strategy aimed at increasing the vegetation cover within the NUAs patches. Thus, this step of the method takes into account the potential of the public acquired NUAs patches to both store and sequestrate carbon. For the purpose of this study, a characterization of NUAs by different land covers was required in order to assess the contribution of different land cover types to carbon uptake. This was conducted by a Land Cover Analysis [7] that allowed to visually identify and digitize six land cover types by interpreting available regional high resolution $(0.25 \mathrm{~m})$ orthophotos (Fig. 2). The contribution of NUAs in terms of carbon uptake has been evaluated through the application of a carbon sequestration rate $\left(\mathrm{kgCO}_{2} / \mathrm{m}^{2} \mathrm{y}\right)$ for each vegetation cover. Potentials of carbon sequestration and storage values for herbaceous vegetation, shrubs and trees have been collected from literature [8], [9], [10] and respectively applied with an average value to the three selected land cover types (Tab. 2). In order to compensate loss of carbon sequestration potential due to urban development within the Development Zones, and enhance the potential of the whole compound, a strategy of new trees plantation is proposed to increase the overall vegetation cover. Moreover, new tree canopies allow to provide supplementary ecosystem services such as microclimate regulation and urban heat islands reduction through their shadow effect. Evaluation of enhancement in terms of carbon sequestration has been conducted before and after the urban development based on TDR program.
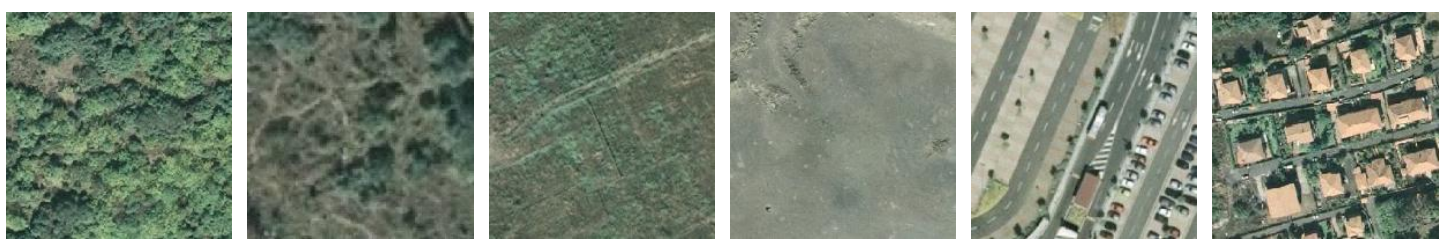

Figure 2: Identified land cover types:

Tree, Shrub, Herbaceous Vegetation, Bare Soil, Impervious, and Building.

\begin{tabular}{ccc}
\hline Land cover types & $\begin{array}{c}\mathrm{CO}_{2} \text { Sequestration } \\
\text { average values } \\
\left(\mathrm{kgCO}_{2} / \mathrm{m}^{2} \mathrm{y}\right)\end{array}$ & References \\
\hline Trees & 1.02 & Nowak et al., 2013 \\
Shrubs & 1.50 & Marchi et al., 2014 \\
Herbaceous vegetation & 1.36 & Getter et al., 2009 \\
\hline
\end{tabular}

Table 2: Carbon Sequestration rates for Trees, Shrubs and Herbaceous vegetation land cover types.

\section{Results and discussion}

The method has been tested within a municipality at the heart of the Catania metropolitan area. According to the criteria for selecting an appropriate site for arranging new public green spaces (see First step of the method), a NUAs patches compound has been identified. Economic feasibility assessment Tool allowed to verify the minimum net profit ratio for the project investment $(\mathrm{P} \%=25.52 \geq 25 \%)$ quantifying the amount of development rights in terms of $\mathrm{FAR}=0,40 \mathrm{~m}^{3} / \mathrm{m}^{2}$ (Tab. 1) and defining the size of the three Development Zones (Fig. 3, red boundaries) and Urban green 
Zone to be acquired for public property (Fig. 3, bold green boundary). Land cover analysis has been conducted within this compound and allowed to identify, through visual interpretation and manual extraction, five different current land cover types (Fig. 3). Results show that Herbaceous vegetation and Shrubs covers are the most prevailing land cover types (respectively $58 \%$ and $31 \%$ ). Trees and Bare Soils cover about $7 \%$ and $4 \%$ while Build- ings represent less than $0.5 \%$ of the total land parcels area (Tab. 3). According to the average values reported in Tab. 2, Herbaceous vegetation covers provide the most relevant carbon sequestration with almost $60,000 \mathrm{kgCO}_{2} / \mathrm{m}^{2} \mathrm{y}$. After the urban development, a total area of 18,237.04 m2 is built up (Fig. 3, within the red boundaries) at the expenses of Trees, Herbaceous vegetation and Shrubs (Tab. 4)

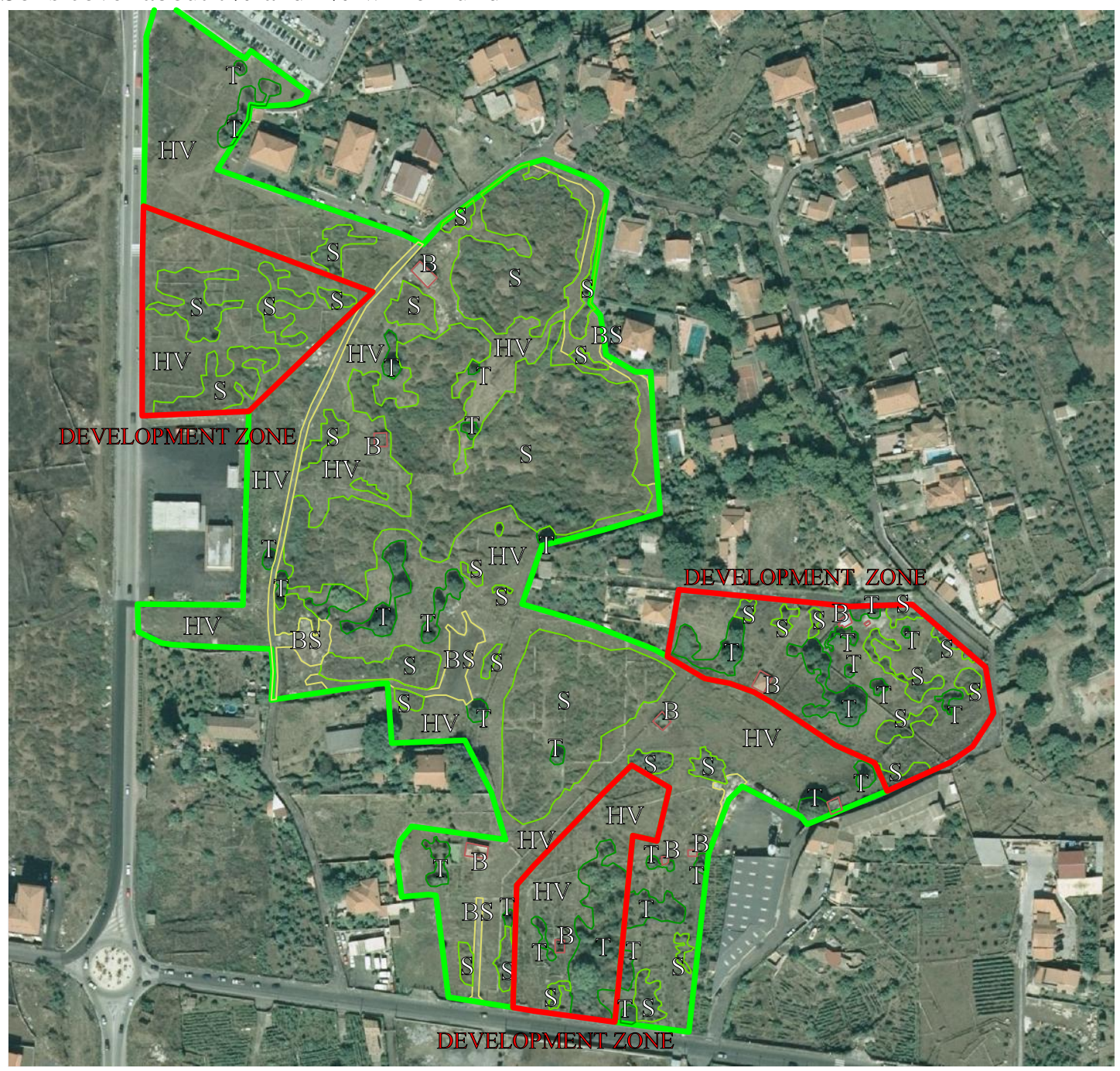

Figure 3: Land cover types as identified through the Land Cover Analysis: Tree (T), Shrub (S), Herbaceous Vegetation (HV), Bare Soil (BS), and Building (B).

At the same time, the plantation of new trees (Fig. 3, within the bold green boundary) allows to add $52,187.29 \mathrm{~m}^{2}$ of Tree cover and provides a supplementary carbon sequestration of 53,231.04 $\mathrm{kgCO}_{2} / \mathrm{m}^{2} \mathrm{y}$. Summing up this contribution to the existing Herbaceous vegetation and Shrubs potentials, a final amount of $125,762.22 \mathrm{kgCO}_{2} / \mathrm{m}^{2} \mathrm{y}$ carbon sequestra- tion potential can be provided. According to this new layout, the total carbon sequestration potential enhancement is more than $30 \%$ when compared to the current layout (Tab 4). Even though the relevance of these results, the proposed method and TDR scenario shows some limitations. Firstly, the methodology doesn't take into account carbon emission potential of new buildings 
within the compound. Moreover, the net profit ratio $(\mathrm{P} \%)$ as checked by the Economic assessment tool is mainly depending on the amount of development rights (FAR) to be granted to private landowners while the percentage of urban green area $(\mathrm{G} \%)$ for public acquisition less influences the economic feasibility of urban development due to its low economic value.

\begin{tabular}{|c|c|c|c|}
\hline Land cover types & Area $\left(\mathrm{m}^{2}\right)$ & $\begin{array}{c}\text { Percentage } \\
\%\end{array}$ & $\begin{array}{c}\text { Carbon } \\
\text { sequestration } \\
\text { potential } \\
\left(\mathrm{kgCO}_{2} / \mathrm{m}^{2} \mathrm{y}\right)\end{array}$ \\
\hline Building & 337,74 & 0,46 & 0 \\
\hline Impervious & 0,00 & 0,00 & 0 \\
\hline Tree & 5100,97 & 6,99 & 5202,99 \\
\hline Herbaceous vegetation & 42293,75 & 57,98 & 57519,50 \\
\hline Shrub & 22462,67 & 30,79 & 33694,01 \\
\hline Bare soil & 2753,03 & 3,77 & 0,00 \\
\hline TOTAL & 72948,16 & 100 & 96416,49 \\
\hline
\end{tabular}

Table 3: Current land covers layout and their carbon sequestration potentials

\begin{tabular}{|c|c|c|c|c|c|c|c|}
\hline Land cover types & s Area $\left(m^{2}\right)$ & $\begin{array}{c}\text { Percentage } \\
\%\end{array}$ & $\begin{array}{c}\text { Carbon } \\
\text { sequestration } \\
\text { potential } \\
\left(\mathrm{kgCO}_{2} / \mathrm{m}^{2} \mathrm{y}\right)\end{array}$ & $\begin{array}{c}\text { Tree } \\
\text { plantation } \\
\left(\mathrm{m}^{2}\right)\end{array}$ & $\begin{array}{c}\text { Tree } \\
\text { plantation } \\
\text { contribution } \\
\left(\mathrm{kgCO}_{2} / \mathrm{m}^{2} \mathrm{y}\right)\end{array}$ & $\begin{array}{l}\text { Total carbon } \\
\text { sequestration } \\
\text { potential } \\
\left(\mathrm{kgCO}_{2} / \mathrm{m}^{2} \mathrm{y}\right)\end{array}$ & $\begin{array}{c}\text { Carbon } \\
\text { sequestration } \\
\text { potential } \\
\text { enhancemen } \\
+\%\end{array}$ \\
\hline Building & $18.237,04$ & 25 & 0 & & & & \\
\hline Impervious & & 0 & 0 & & & & \\
\hline Tree & 2523,83 & 3 & 2574,31 & 52187,29 & 53231,04 & & \\
\hline Herbaceous v. & 29960,83 & 41 & 40746,73 & & & & \\
\hline Shrub & 19473,43 & 27 & 29210,15 & & & & \\
\hline Bare soil & 2753,03 & 4 & 0,00 & & & & \\
\hline TOTAL & 72948,16 & 100 & 72531,18 & & 53231,04 & 125762,22 & 30,44 \\
\hline
\end{tabular}

Table 4: Land cover types areas, percentages and carbon sequestration potential

This implies that the economic profit of the project is strictly related to the amount of resulting built-up areas that will be responsible of new additional carbon emissions. Secondly, the proposed tree plantation strategy represents a scenario aimed at maximizing carbon sequestration and other ecosystem services but could be appear highly theoretical. Indeed a total tree coverage is not realistic because designing urban green spaces implies to identify different zones for leisure such as lawns, pathways, bike lanes, water bodies, and playgrounds. As an alternative, a more suitable strategy could be take into account a mixed plantation of trees and shrubs in order to compensate loss of sequestration potential due to leisure zones (to be considered as bare soil and herbaceous vegetation/grass).

\section{Conclusions}

This study presents a possible way to implement new public urban green spaces at reduced costs for the local administrations through the allowance to private landowners of a very limited amount of new development and soil consumption. This represents a reasonable trade-off for the free of charge transfer to public property of their land parcels designated for green spaces and the opportunity to enhance their carbon sequestration potential. Moreover, applying Transfer of Development Rights strategy would help to develop new public urban green spaces throughout the city, implement climate change adaptation strategies, create a more liveable and healthy urban environment and obtain economic benefits for landowners and de- 
velopers of areas designated for green spaces and local administrations that may implement public services with no or limited financial efforts.

\section{References}

[1] La Rosa, D. \& Privitera, R. Characterization of non-urbanized areas for land-use planning of agricultural and green infrastructure in urban context. Landscape and Urban Planning, 109, pp 94-106, 2013.

[2] McHale, M.R., McPherson, E.G., Burke, I.C. The potential of urban tree plantings to be cost effective in carbon credit markets. Urban Forestry \& Urban Greening, 6, pp 49-60, 2007.

[3] Privitera, R., \& La Rosa, D. Transferability of Greencities experiences for sustainable urban planning. International Scientific Conference Geobalcanica 2015 Proceedings, ISSN 1857-7636, pp 127-134, 2015.

[4] Bengston, D.N., Fletcher, J.O., Nelson, K., C. Public policies for managing urban growth and protecting open space: policy instruments and lessons learned in the United States. Landscape and Urban Planning, 69, pp 271-286, 2004.

[5] Brabec, E., \& Smith, C. Agricultural land fragmentation: the spatial effects of three land protection strategies in the eastern United States. Landscape and Urban Planning, 58, pp 255-268, 2002.

[6] Martinico, F., La Rosa, D., Privitera, R. Green oriented urban development for urban ecosystem services provision in a medium sized city in southern Italy, iForest, 7(7), pp 385-395, 2014.

[7] La Rosa, D., Barbarossa, L., Privitera, R., Martinico, F. Agriculture and the city: A method for sustainable planning of new forms of agriculture in urban contexts. Land Use Policy, 41, pp 290-303, 2014.

[8] Nowak, D.J., Greenfield, E. J., Hoehn R.E., Lapoint, E. Carbon storage and sequestration by trees in urban and community areas of the United States. Environmental Pollution, 178, pp 229-136, 2013.

[9] Marchi, M., Pulselli, R.M., Marchettini N., Pulselli, F.M., Bastianoni, S. Model Carbon dioxide sequestration model of a vertical greenery system. Ecological Modelling, 306, pp 46-56, 2014.

[10] Getter, K.L., Rowe, D.B., Robertson, G.P., Cregg, B.M., Andresen, J.A. Carbon sequestration potential of extensive green roofs. Environmental science \& technology, 43, pp 7564-7570, 2009. 